\title{
Un presunto caso de complicidad diabólica en el siglo XVIII: Alonso de Osuna y las religiosas del convento de Santa Clara de Antequera
}

\begin{abstract}
Me considero en la obligación más estrecha de manifestar ingenuamente a V.A. que cada día encuentro en la complicidad imaginada, y sus causas respectivas a cada uno, más graves motivos de suspender el juicio, o por mejor decir de inclinarlo a que esta máquina es en su general parte, montaña de humo que formó su cuerpo con anticipada aceleración antes que lo entendiese el Tribunal por el indiscreto zelo o culpable malicia del confesor ordinario de aquel tiempo, Fray Agustín Ponce que soñaba voluntariamente lo que las monjas jóvenes con ilusión imaginaban o lo que él, acaso, las sujería con ninguna cordura o culpable dolosa curiosidad de indagar delitos que no había.

(El Inquisidor Don Juan Jacinto de Varaez, Correspondencia entre el Tribunal de Granada y el Consejo de la Suprema y General Inquisición, A.H.N. Inq., legajo 2692, expediente 129)
\end{abstract}

Una investigación desarrollada en el Archivo Histórico de Madrid sobre la brujería en el siglo XVIII, nos proporcionó un caso relevante por el gran número de personas implicadas, así como su oficio y el ámbito en que se desarrolla. El nudo de esta historia se relaciona con un grupo de monjas "en la ciudad de Antequera, [donde] hay un convento de religiosas franciscanas con el título de Santa Clara de la Paz, sujetas a la religión del Señor San Francisco" ". Su calidad de monjas contrasta violentamente con los hechos revelados a lo largo de la indagación llevada a cabo por el Tribunal del Santo Oficio de Granada en la segunda mitad del siglo XviII.

Analizaremos a continuación un caso de "epidemia onírica", según expresión de Gustav Henningsen ${ }^{2}$, de la que fueron víctimas sus moradoras. Este acontecimiento sacudió el tranquilo convento de Santa Clara

1 AHN, Inq. Leg. 2692, Exp. 92. Para la transcripción de los manuscritos manejados, hemos actualizado generalmente la ortografía y la puntuación.

2 Gustav HENNINGSEN, El abogado de las brujas. Brujeria vasca e Inquisición española, Versión española de Marisa Rey-Henningsen (Madrid: Alianza, 1983), la primera edición en inglés data de 1980. Gustav Henningsen estudia en su obra uno de los más famosos procesos de brujería acaecido en Logroño, entre 1610 y 1614 . Pone de relieve el previo adoctrinamiento que conduce a "los sueños estereotipados" que "se caracterizan por la impresión de realidad que dejan y lo bien que se recuerdan al despertar", pp. 343-344. Es interesante, asimismo, la referencia que este autor hace de la expresión .lavado de cerebro* (p. 67) que, en su opinión, estuvo presente en las prácticas pro- 
de Antequera, imaginándose las religiosas cómplices de unas aventuras brujeriles que las llevaron, según creyeron, a concurrir a juntas diabólicas encabezadas por el demonio, quien intervenía bajo la apariencia de un mozo llamado Alonso de Osuna, natural y vecino de la ciudad de Antequera, de ejercicio organista.

Dio origen a la "epidemia" el esmero que pusieron algunos confesores en descubrir una posible complicidad diabólica en el seno mismo del convento, a raíz de la atracción amorosa que sintieron una de las monjas y el joven citado, profesor de música que daba clases en el convento. Aunque no se trata de un caso de solicitación ${ }^{3}$, merece recordar los peligros a que se veían expuestos los confesores de conventos según Juan Antonio Llorente:

Un gran número de delaciones [por solicitación en el confesionario] es de monjas escrupulosas y simples, cuya imaginación femenina, exaltada, no se tranquiliza sino denunciando en caso de duda; exponiendo la honra, libertad y fortuna de su prójimo: casi siempre son infundadas, despreciables y nacidas de mala interpretación de las palabras del confesor. Si los aficionados a confesar monjas viesen los papeles del Santo Oficio, perderían su inclinación a la vista del peligro que les amenaza. Por fortuna los inquisidores de los últimos tiempos estaban ya, generalmente hablando, persuadidos de que debían despreciar la delación de monja que no se fundaba en proposiciones positivamente inhonestas, o hechos claros e intergiversables ${ }^{4}$.

\section{Doña Rosa Montilla y Alonso de Osuna: historia de UN AMOR IMPOSIBLE.}

Todo empezó con unas clases de música, aparentemente inocuas por cuanto la reja del locutorio impedía todo contacto íntimo entre la religiosa y su maestro.

Dona Rosa Montilla, religiosa profesa y de coro de Santa Clara de Antequera, con licencia de su prelada, bajaba todos los días al locutorio a tomar lecciones de música, que se la daba Alonso de Osuna, mozo soltero: dieron en acudir otras

cesales de la Inquisición. Dada su semejanza, hacemos extensivo este concepto a las actuaciones del confesor del convento de Santa Clara, según nuestro enfoque desarrollado en el epígrafe II.

3 La "solicitación" era un delito castigado por el santo Oficio, producido cuando el confesor requería de amores a la penitente.

4 J. A. LlORENTE, Historia Crítica de la Inquisición en España (Madrid: Hiperión, 1980 y 1981), 4 tomos, tomo III, p. 30. (La primera edición se publicó en París, en francés por Treuttel y Wurtz en 1817-1818 y la primera versión en castellano en 1822). 


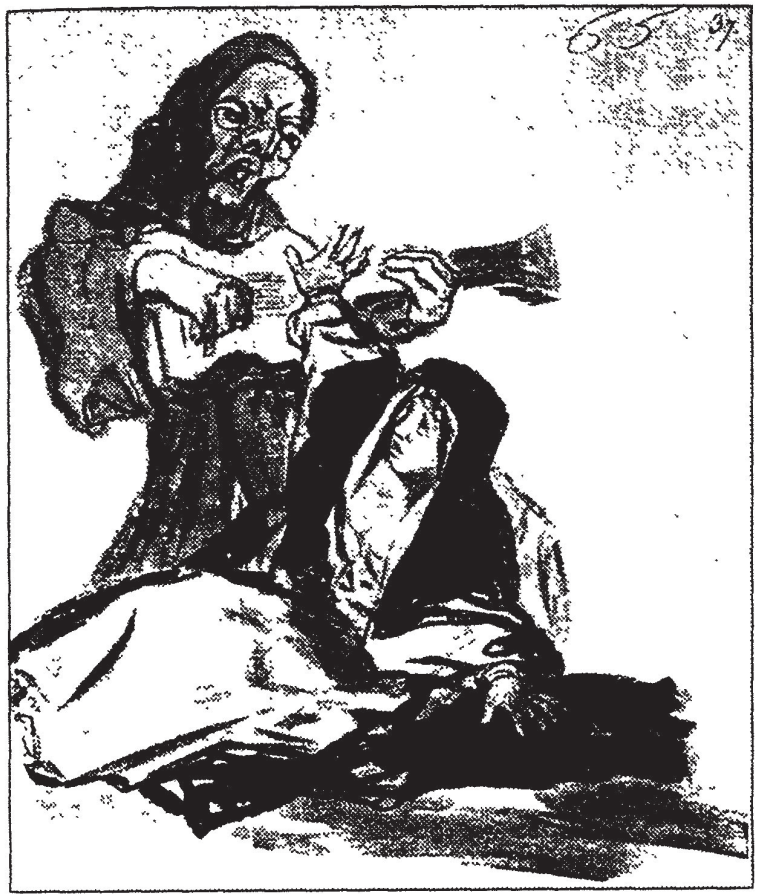

FIG. 1.-Monja tentada por la música de un fraile-fantasma. Goya, Les dessins de Goya: Les Albums, Pierre Gassier (1803-12; $205 \times 145$, S. N. ${ }^{\circ}$, N. $^{\circ}$ post. 37)

religiosas mozas, y llegaron a cobrarse tanto cariño la Montilla y Osuna, que ya causaban escándalo con sus recíprocos dichos, papeles y tocamientos. La prelada y religiosos superiores, con este motivo, prohibieron el que bajase la Montilla, y el que entrase allí Osuna. Dio en cavilar la Montilla con este sentimiento y el Osuna no dejaba de entrar en la Iglesia, a tiempo que las religiosas estaban en el coro, y aun tosía, para que le sintiese su discípula 5 .

Ese amor imposible hubiera podido terminar con la separación forzada que sufrieron los dos personajes. Sin embargo, un hombre clave en la vida de las religiosas, su confesor, iba a desencadenar un proceso largo y tumultuoso, en que se vieron implicadas un gran número de monjas del convento y muchas personas exteriores, en su mayoría religiosos. Se transcribe en las alegaciones fiscales que

empezó a contar sus sentimientos, cavilaciones y sueños la Montilla al confesor del convento, que era fray Agustín Ponce, hombre nimiamente crédulo, y dio tanto en perseguirla sobre que no eran sueños o cavilaciones, sino realidades, que hostigada la religiosa de tanta instancia y persecución sobre que dijese por menor todo cuanto la pasaba, que por complacerle, fingió de palabra y por escrito en varias cartas, cuantos desatinos se la ofrecían, y había leído en varios libros de novelas. En estos desatinos refirió encantamientos, conventículos y otras concurrencias $^{6}$.

La versión de los hechos revelados por Alonso de Osuna en audiencia voluntaria el 8 de abril de 1766 nos permite conocer mejor a este joven que sintió una indudable atracción por la monja. Ese amor compartido explica el empeño del mozo en seguir comunicando con su amada, a pesar de ser descubiertos, no dudando en ponerse en peligro por ello. La frustración de esa relación fue lo que llevó a la religiosa a imaginar y soñar lo que no podía vivir. Alonso de Osuna, declaró ante el tribunal que

\footnotetext{
5 AHN, Inq. Leg. 3723, Exp. 129.

6 Ibid.
} 
desde los diez años de su edad, empezó a incurrir en lascivias y pecados deshonestos de poluciones consigo y con otras varias personas de todos estados. Que habría tres años, con motivo de ser el declarante músico, concurrió a un locutorio o grada del convento de Santa Clara, empezó a tratar a la religiosa doña Rosa Montilla, la que manifestó quería que el declarante la enseñase la música, a que este reo condescendió gustoso, y en efecto después de haber pasado algún tiempo en lecciones de música, empezaron ambos a manifestarse desordenado afecto, tratándose con mucho cariño y con la expresión de esposos, dándose las manos por las rejas del locutorio y torno y en cuanto podían, se tocaban los dedos. Que creciendo el desorden, se dieron mutuamente algunos cabellos de su cuerpo o partes ocultas, sin que hubiesen tenido acto carnal alguno, ni dentro ni fuera del convento, ni que se hayan visto descubiertos. Que este mal trato duró cosa de seis o siete meses, hasta que descubrieron en el convento que la Montilla regalaba a este reo y con este motivo prohibieron a ésta la comunicación y al reo, por medio de la tornera, dijeron no volviese a dicho convento. Que en efecto no volvió a las gradas ni locutorios, sí sólo ha pasado por la calle y entrado en la Iglesia, tosiendo, y con otras demostraciones de algún escándalo, todo a fin de ver a dicha Montilla. Que es cuanto tiene que decir y lo que presume sea causa de su prisión. Dio su genealogía, diciendo que todos han sido cristianos viejos... [afirma quel sólo ha faltado a los mandamientos de la ley de Dios en las especies de lujuria, que tiene dichas, sin pensar que por ellos se le tuviese por hereje ${ }^{-}$.

Este fue, en efecto, el motivo por el que Alonso de Osuna compareció ante el Santo Oficio, siendo internado en la cárcel secreta "por delitos de Idólatra, Apóstata, sortílego con pacto explícito" ${ }^{8}$. Al principio de su proceso, el joven ignoraba el motivo de su detención, ya que a los procesados sólo se les anunciaba la acusación de que eran objeto después de varias audiencias por lo que tenían que defenderse sin saber quién les había delatado ni porqué. J. A. Llorente, en su Historia Crítica de la Inquisición en España, explicó en qué consistía el secreto en que el Santo Oficio mantenía a los acusados:

Ningún preso ni acusado ha visto jamás su proceso propio, cuanto menos los de otras personas. Ninguno ha sabido de su causa más que las preguntas y reconvenciones a que debía satisfacer, y los extractos de las declaraciones de testigos, que se le comunicaban con ocultación de nombres y circunstancias de lugar, tiempo y demás capaces de influir al conocimiento de las personas, ocultándose también lo que resulte a favor del mismo acusado, porque se seguía la máxima de que al reo toca satisfacer el cargo, dejando a la prudencia del juez el combinar después sus respuestas con lo que produzca el proceso a favor del procesado ${ }^{9}$.

\section{Ibid.}

8 AHN, Inq. Leg. 2692, Exp. 144.

' J. A. LlORENTE, Historia Crítica de la Inquisición en España, op. cit., tomo I, p. 3. 
Para defenderse, y creyendo que doña Rosa Montilla había sido quien le delató, argumentó que

nunca llegaron ni pudieron, a acto carnal, por la imposibilidad del sitio. Que no la conocía en el siglo ${ }^{10}$, ni tenía noticia de ella, lo que se evidencia de la mucha mayor edad que ésta tiene. Que jamás ha entrado este reo en el convento, ni por pacto, ni por otro medio, ni sabe cómo está por dentro.

En realidad, doña Rosa Montilla no delató al mozo a la Inquisición pero como fray Agustín Ponce

creyó todos los disparates que soñó, y forjó la Montilla, reconvino a otras religiosas, y aunque éstas al principio le negaban, y aun decían que jamás habían oído tales géneros de pecados, como las decía en sus respectivas confesiones que no se cansasen en negarlo, pues había dieciocho testigos, que lo aseguraban, les hizo creer que habían sido cómplices, y aun por consejo suyo, se hicieron en el Tribunal de Granada varias delaciones voluntarias, en que refieren muchas juntas de monjas, frailes, clérigos y otros seglares, partos e infanticidios, comercio con el demonio, etc.

La obsesión del confesor por la actuación del diablo provocó unas reacciones cuyas consecuencias rebasaron los límites del convento, ya que muchas personas se vieron involucradas en el proceso en calidad de cómplices o testigos.

\section{El "LAVADO DE CEREBRO" Y SU CONSECUENCIA: LA PRIMERA DENUNCIA}

Una de las religiosas que creyeron al confesor fue doña María de los Dolores Montero, religiosa de velo negro en el convento de Santa Clara de Antequera. El 21 de enero de 1764, compareció delatándose, y declarando por cómplice a Osuna. Mandó una carta al Tribunal de Granada en la que decía que llevaba cuatro años de profesión y que

se refugió a aquel convento deseando salvar su alma, pero que no lo podía conseguir a causa de que un mozuelo ocioso, que la persiguió en el siglo torpemente, después la ha perseguido en los seis años que lleva de convento, por arte del diablo, apareciéndose personalmente de día y de noche con gravísimo peligro de su honor y vida porque la castigaba su resistencia y amenazaba de muerte sin hallar asilo a su desgracia.

Lo delataba "para que el tribunal pusiese remedio a esta pobrecilla afligida que deseaba con ansia su salvación y mirase por su honor, el de

10 "Siglo": "Comercio y trato de los hombres en cuanto toca y mira a la vida civil y política, en oposición a la vida religiosa.. Diccionario de la Lengua Española de la Real Academia. Edición de 1992. 


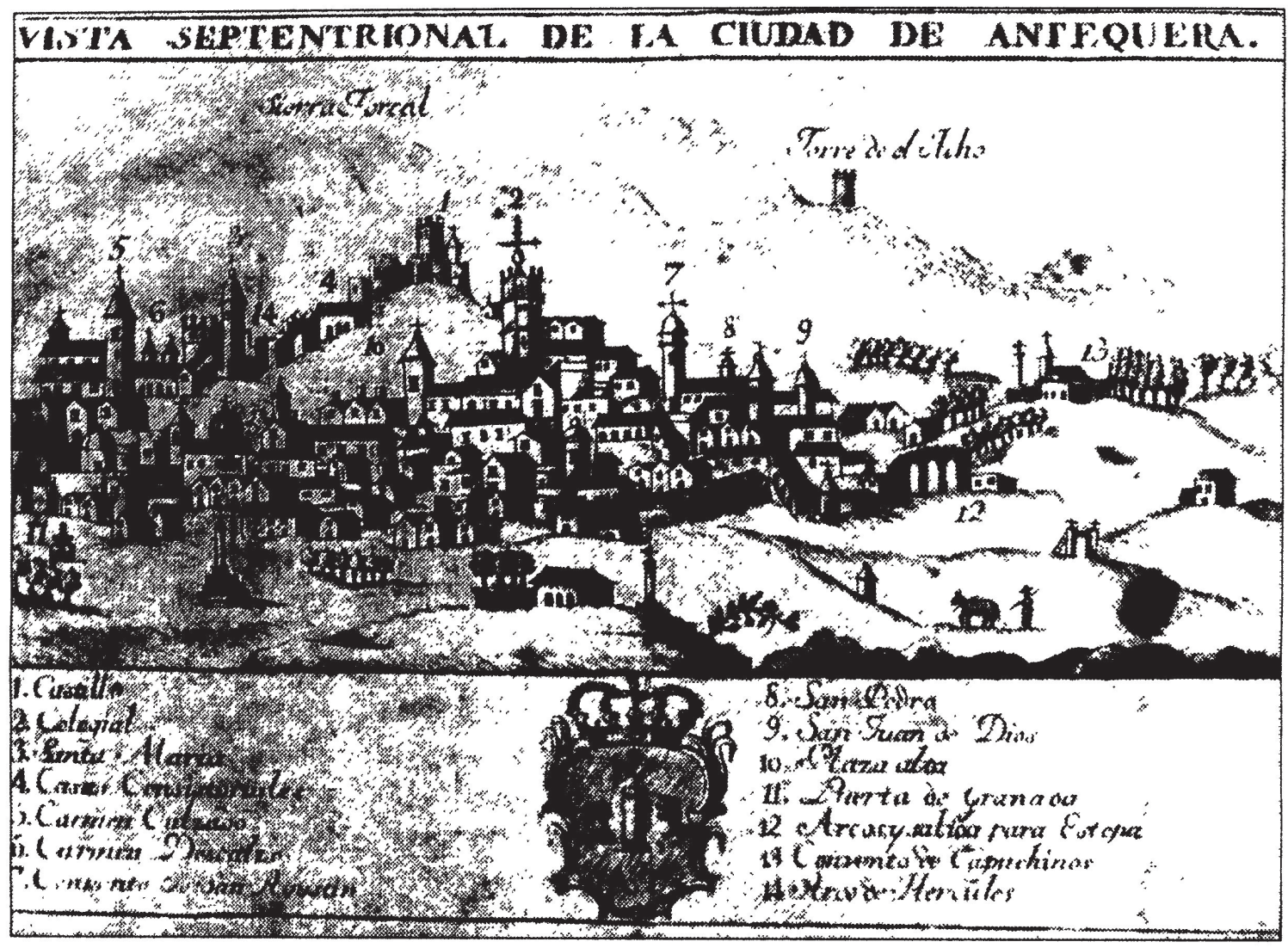

Fig. 2.-Vista de la ciudad de Antequera. Xilografía.

su familia, convento, que este mozuelo se llama Alonso de Osuna, y así lo delata por hechicero, pervertidor de nuestra Santa Fe." Afirma, asimismo, que a la solicitud de Alonso de Osuna "había practicado algunas obscenidades en uno de los locutorios del convento, y que después, éste se le había aparecido o representado personalmente en igual solicitud." Hizo esta delación por orden de su confesor, Fray Agustín Ponce, religioso de la observancia y confesor ordinario de dicho convento ${ }^{11}$.

Se sucedieron entonces, una serie de acusaciones y retractaciones por parte de la religiosa. Fue examinada el 31 de marzo de 1764 por el comisario don Miguel López Conejo quien declaró que "no hizo juicio padeciese ésta debilidad de cabeza ni que fuese demasiadamente aprensiva, lo que se conocía por la formal conversación. Que asimismo, se le había informado que su confesor era sujeto literato y de loable opinión, como lo acreditaban los remedios que aplicó a la delatora" ${ }^{12}$.

El 13 de julio de 1764 Sor María de los Dolores Montero hizo otra delación voluntaria, diciendo que «tenía de edad 23 años cumplidos, de profesión cinco, y diez de estancia en el convento». Después de contra-

11 AHN, Inq. Leg. 3723, Exp. 129.

12 Ibid. 
decirse varias veces, firmando en algunas ocasiones y declarando que no sabía firmar en otras, quiso revocar sus declaraciones anteriores porque

en ellas se contenían delitos que no había cometido. Que es cierto se ha desesperado e invocado al demonio y aún ha dicho con la misma desesperación que vinieran todos los demonios del infierno y entraran en su cuerpo, pero que luego se arrepentía y dolía de ello. Que es falso haya tenido esta declarante trato, ni pacto con el demonio, ni con el secular que cita en su primera declaración, ni ha tenido comunicación alguna con él ni amistad. Que asimismo es falso haya esta declarante salido del convento y clausura por arte del demonio, o que haya entrado dicho secular en la clausura, pues todo ha sido representación de su imaginación tan viva, que llegó a creer fuese realidad, aunque al principio no fueron más que pensamiento y ocurrencia ${ }^{13}$.

Sor María terminó declarando que todo había sido falso y soñado, permaneciendo "negativa", es decir negando las acusaciones, hasta el final del proceso. Sin embargo, ya era tarde. Pronto llegaron nuevas delaciones provenientes de otras religiosas del convento, la "epidemia onírica" se había extendido poco a poco a toda la comunidad. El "lavado de cerebro", ejercido por el confesor, alcanzó tal punto que la propia Rosa Montilla acabó denunciando a Alonso de Osuna, creyendo firmemente haber incurrido en el delito de hechicería y perpetrado actos dignos de los peores relatos de brujería.

\title{
III. EL DELIRIO COLECTIVO O LA "EPIDEMIA ONÍRICA"
}

Perseguidas e instigadas por su confesor, la mayoría de las religiosas acudieron a denunciarse ante el Tribunal del Santo Oficio, declarando que Alonso de Osuna era quien dirigía toda la maraña.

Por descubrir estos crímenes, acudía dicho Agustín Ponce a todas las horas del día al confesionario y aún a media noche, y se llevaba mananas, tardes y noches enteras en estas indagaciones. El citado Osuna resultaba reo en todas las juntas, y creyendo el tribunal que con su prisión se descubriría la complicidad, porque así informaba el Comisario de Antequera, que es Canónigo de oficio, y que era sujeto divertido, se le aseguró en cárceles secretas, sin haberse consultado al Consejo ${ }^{14}$.

El empeño del confesor en ver complicidades diabólicas por todas partes, llevó a algunas religiosas muy jóvenes del convento a contar unas historias inverosímiles y espeluznantes que describieron a los ministros del Santo Ofi-

\author{
13 Ibid. \\ 14 AHN, Inq. Leg. 2692, Caja 1, Exp. 120.
}


cio, encargados de recoger sus declaraciones. Sólo reproduciremos las partes más relevantes que reflejan el poder sugestivo del discurso del confesor.

Doña Josepha María Casasola, y su hermana doña María Josepha se delataron por primera vez los días 11 y 14 de agosto de 1764. El 4 de septiembre, esta última, amplió su declaración, acusando a otras tres religiosas

que la persuadieron a que concurriese carnalmente dentro de la clausura con el referido Alonso de Osuna, a que asintió y presenció los actos que tenía con las demás a media noche y que muchas veces se hallaba fuera de la clausura, en algunas casas y en el campo sin saber cómo, con las dichas religiosas, el referido Alonso de Osuna y otros hombres religiosos, con quienes todas tenían el mismo comercio carnal ${ }^{15}$.

Casi en las mismas fechas, Sor Josepha María, añadió como cosa singular "la particularidad de haber hecho cédula al demonio de entregarle su alma y cuerpo con el fin de que la sacara del convento para tratar libremente con hombres, cuya cédula hizo y firmó con sangre de su cuerpo" ${ }^{16}$.

Llamada a declarar la novicia Sor María San Rafael Losada, de 16 años, describió, con todo lujo de detalles, abominables asambleas satánicas. Sus declaraciones eran dignas de los más horrorosos relatos de brujería con todos los ingredientes peculiares tales como los ungüentos, los vuelos nocturnos para trasladarse al conventículo donde adoraban al demonio, sin olvidar los crímenes más horrendos como los infanticidios. En su primera delación, sólo mencionaba a cuatro personas; sin embargo, unos meses después, con ocasión de nuevas denuncias, alargó la lista de los cómplices. Sus descripciones meticulosas y apasionadas revelan hechos relacionados con

juntas nocturnas fuera y dentro del convento con varias religiosas y religiosos y Alonso de Osuna, en las que concurría el demonio en figura de perro, a quien adoraban y osculaban y con quien también se mezclaban carnalmente [...], y que para salir de la clausura se untaban varias partes de su cuerpo con un ungüento que parece se componía de sangre humana, hostias consagradas que reservaban los días de comunión y otras reliquias y con sangre de los infanticidios que hacían de las criaturas y embarazos que resultaban de estas juntas, de cuyo ungüento usaban los varones a la parte de afuera para introducirse en la clausura para dichas juntas, que eran muy repetidas ${ }^{17}$.

Llevada por su vehemencia juvenil o tal vez por sus fantasías eróticoreligiosas, la declarante hace una descripción irreverente de los rituales de

\footnotetext{
15 AHN, Inq. Leg. 2692, Exp. 92.

16 Ibid.

1- Ibid.
} 
UN PRESUNTO CASO DE COMPLICIDAD DIABÓLICA...

RDTP, L, 1, 1995

229

Uexorimititud relo relacionad fidtactoryta, en quans à existencia re liburs, y formu= laxion Concextrita ales abominables avam=

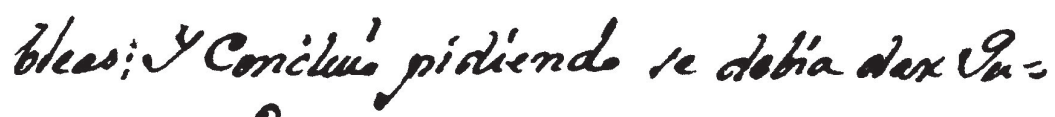
inta : P. L. añadiende, que anoer reppes.

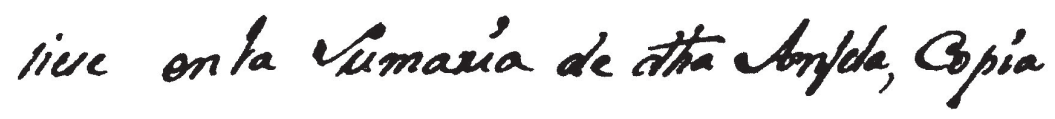
dela diliso preacticadta pr los Pexisos enel he. nocim." delor \%otes, y Barilas, que re hallas = zon en la Colda de D.P. Tora Montilla àel tiempo desu Prision, y que gual xeconoci= miense re hicive selor que pl mans de

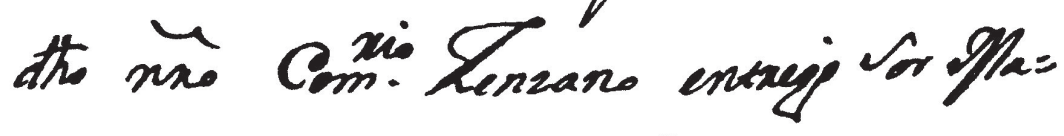
nia de Van Rafael Lorada, Hexmana de atha Ornfela, el que haviendere practi'= cado por dor Macestur de Boticaxion yy á pxuencia del Thedica y Comefaro de ester Sante of. xeconocienon ticte Bailas peques nas,y hallasen etrálqunas, no poder dis:

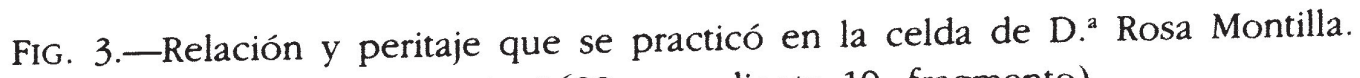
(A.H.N. Legajo 2692, expediente 19; fragmento).

(c) Consejo Superior de Investigaciones Científicas

http://dra.revistas.csic.es/

Licencia Creative Commons Attribution (CC-by) 4.0 España. 
adoración al demonio, firmando cédulas de obediencia "con sangre menstrual y algunas con sangre de las heridas de los pechos que se hacían, y renegando de Dios, de María Santísima, Santos y Santos Sacramentos, pisando con desprecio una imagen de Cristo crucificado, sagradas formas que reservaban a las comuniones, usando de unturas supersticiosas".

El punto culminante de su intervención, se refleja en los detalles cruentos que proporciona al narrar sus actividades conventuales:

[En el cáliz] recogían el semen y sangre menstrual limpiándose con las purificaciones sus partes verendas, y aquellas inmundicias, aplicándose también a dichas partes las mismas formas consagradas y terminando estos actos con los carnales que tenían unos con otros, usando también de dicha untura para salir de la clausura las religiosas y demás concurrentes e ir, ya a las celdas de los religiosos, ya al campo, y ya a casas particulares de los mismos cómplices, donde alternaban y repetían los mismos actos, que finalizados usaban de la misma untura para volverse a la clausura, cuya untura la aplicaban bajo de los brazos, las palmas de las manos, orificio, partes pudendas, corvas, rodillas, las sienes y palmas de los pies.

También alude a bebidas preservativas para evitar los embarazos y dice que aquellas religiosas que no las usaban o no tenían efecto:

luego que parían, degollaban el infante, le cortaban la cabeza y recogían la sangre que mezclaban con dicha untura, enterrando unos dentro de la clausura y otros se los llevaba fuera de ella el Alonso de Osuna, siendo repetidos los partos e infanticidios, que presenció algunos la delatante y de otras era sabidora de que habían parido porque ella misma les había descargado después los pechos de leche ${ }^{18}$.

La imaginación desbocada de la monja la llevó a delatar, el 30 de abril de 1766 , hasta ochenta y ocho personas. Su delación incluía a

cuarenta y una religiosas entre Profesas de Velo Negro y Blanco, dos Novicias y dos Pinzetas, que este nombre les dan a las que están de seglares para tomar el hábito, siendo entre dichas religiosas cómplice la actual abadesa y otras que lo han sido y de religiosos de varias religiones y sacerdotes seculares y otras personas seculares, así hombres como mujeres de todos estados, que llega su número a cuarenta y siete, y todos los cómplices de dentro y fuera asciende al número de ochenta y ocho ${ }^{19}$.

Como consecuencia de todas estas declaraciones, se ordenó llevar a cabo unas pesquisas en el convento, para encontrar libros sospechosos o cualquier tipo de objeto mágico. La investigación fue encargada al visitador fray Pedro Romero, con asistencia del Comisario del Santo Oficio de

\footnotetext{
18 AHN, Inq. Leg. 2692, Exp. 139.

19 Ibid.
} 
Antequera, don Francisco Ruiz Zenzano, llevándose a cabo en $1770^{20}$. En opinión de los informantes, no se hallaron ni libros ni papeles sospechosos relativos al asunto investigado ${ }^{21}$. Sin embargo, sí se encontraron objetos que dieron lugar posteriormente a un informe pericial. Fueron hallados botes y vasijas cuyo contenido fue analizado por dos Maestros de Boticarios, en presencia del médico y cirujano del Santo Oficio. "Reconocieron siete vasijas pequeñas y hallaron en algunas, no poder distinguir lo que contenían, y en otras contener un compuesto de materias piguedinosas que no podían tener otro uso que para fines supersticiosos." Otros aspectos del informe quedan reflejados en el siguiente párrafo:

Lo que resultó de la inspección hecha por dichos peritos, de los botes y vasijas que se hallaron al tiempo de la prisión de la referida Montilla, fue que en uno apareció la sospecha de ser su composición semen humano, sangre menstrual, y vello de partes pudendas de varón o hembra o de ambos, recelando fuese especie de filtro a fin de conciliar violentamente amor en alguna persona. En otro, parece ser su composición de hormigas, cochinillas o milepedes en líquido oleoso, cuyas virtudes en el común sentir de médicos y boticarios son ad venus estimulandum. $\mathrm{Y}$ en otro, contener una sustancia adiposa, y un pedacito de película o primer cutis humano; persuadiéndose que en esta composición hubiese algún sebo de infante por su suavidad y color y alguna otra cosa que lo vuelve más líquido que lo que le corresponde, sin alcanzar a conocer cual sea por la mixtura que lo confunde, y en el orden médico y quirúrgico puede aplicarse a varios efectos como era quitar señales de heridas, suavizar el cutis áspero. Y en el resto de la vasija que se les demostró encontraron varios medicamentos conocidos para enfermedades naturales ${ }^{22}$.

20 AHN, Inq. Leg. 2692, Caja 2, Exp. 168. Los manuscritos mencionan una visita que hizo al convento en 1764 fray Pedro Romero, de cuya resulta se delataron la mayor parte de las monjas. No tenemos más datos sobre esta intervención; sin embargo, sí es interesante detenerse en la personalidad del visitador, que aflora en un memorial presentado en marzo de 1772 a raíz de su alejamiento de Antequera. Imploraba en él su regreso para servir la guardianía del convento de San Francisco een vista de ahogar los rumores según los cuales había salido de Antequera castigado por el Santo Oficion a causa de su conducta en la complicidad de las religiosas de Santa Clara. En su memorial demuestra su credulidad en materias supersticiosas, alude a los peligros que le amenazaban, escribiendo que las religiosas "por dos veces me dieron maleficio, y que se admiraban que no hubiese tenido efecto, y otra vez me avisaron de adentro, que me tenían prevenido otro maleficio, por cuyo motivo no entré a visitar la clausura." El impacto de su actuación sobre las monjas puede entenderse mejor cuando alega para su defensa: sla buena intención con que por más de seis años he solicitado por los medios que me parecieron prudentes la reducción de aquellas religiosas ilusas al desengaño a costa de grandes desazones y no pequeños peligros.n

${ }_{21}^{21}$ AHN, Inq. Leg. 2692, Caja 1, Exp. 120. 
Las dos monjas responsables del delirio colectivo tuvieron un fin desdichado ya que doña Rosa Montilla falleció el 31 de octubre de 1767 siendo presa en la cárcel secreta, retractándose y habiendo permanecido negativa en los cargos de la acusación ${ }^{23}$. En cuanto a Doña María de los Dolores Montero, se retractó un día, afirmando haber hecho todas sus declaraciones "por la eficacia con que su confesor, fray Agustín Ponce la persuadió a que todos eran hechos verdaderos, y que él, los sabía por revelaciones que refería". Será finalmente desterrada a otro convento. Por lo que se refiere a Sor María Josepha Casasola, también revocó su anterior delación espontánea contra sí misma y sus cómplices, aduciendo similares "persuasiones de este confesor" ${ }^{24}$.

\section{LA DEFENSA DE ALONSO DE OSUnA}

Alonso de Osuna, de unos veinte años de edad, vivía en Antequera con su padre cuando fue delatado al Santo Oficio. Había sido tiple de la Colegiata de dicha ciudad, pero al perder la voz, se aplicó al órgano, que solía tocar en la misa mayor en el convento de los Remedios. Ayudaba también a su padre en sus menesteres de barbero. El 31 de marzo de 1764, el comisario don Miguel López Conejo declaró: "que no está mal opinado ni notado de vicioso" ${ }^{25}$. Pero al ir acumulándose las testificaciones contra él, comprobamos que el tono empleado por los inquisidores cambió radicalmente en la calificación emitida dos años más tarde:

Sacóse extracto y visto por tres calificadores en lo objetivo dijeron contenía pacto expreso con el demonio con frecuente trato y comercio con él, sortilegios, magias, apostasía, idolatría. Y al sujeto de idólatra, apóstata, sortílego y por consiguiente por sospechoso de vebementi.

El 18 de marzo de 1766, el Tribunal acordó encarcelarle con secuestro de bienes. El 24 del mismo mes dio con sus huesos en la cárcel ${ }^{26}$.

Cuando se le presentó la acusación, Alonso de Osuna intentó justificarse manifestando unos detalles de su vida que mostraban la atmósfera supersticiosa que imperaba en la sociedad dieciochesca. Ante los inquisidores confesó que "se valió de dos mujeres que nombra, dependientes del convento, para que diesen algunos recados o papeles a la Montilla,

\footnotetext{
23 AHN, Inq. Leg. 2692, Exp. 196.

24 AHN, Inq. Leg. 2690, Exp. 61.

25 AHN, Inq. Leg. 3723, Exp. 129.

26 Ibid.
} 
y no sabe que éstas tengan nota de hechiceras, ni que hayan subministrado bebidas, o ungüentos para facilitar salidas al campo".

Alonso de Osuna, con una clarividencia que contrastaba con la actitud del confesor, declaró en diciembre de 1766 que "por los mismos cargos se conoce son ilusiones y no realidades los que refieren los testigos, y que por consiguiente se halla inocente este reo, pues no tiene la culpa de que el diablo tomase su figura para tantos males". Prosiguió negando todos los cargos, alegando que de seguro todas estas cosas habían sido

ilusiones del diablo engañando a estas gentes, haciéndolas creer que él intervenía en estos asuntos, que le escandaliza el oírlos, y no cree que religiosas consagradas a Dios, hayan tenido y tengan una vida tan relajada, como la que se expresa, por lo que duda si los testigos, que le han acusado, tengan cabal juicio, para decir con verdad tanto cúmulo de desatinos y desórdenes como se refieren y horrorizan a cualquier católico, aunque sea de vida relajada. Que sólo es cierto lo que tiene dicho de su incontinencia, sin que haya intervenido en pactos, unturas, supersticiones. Por lo que implora al tribunal aclare la verdad pues sea sin culpa en tales asuntos ${ }^{27}$.

Su defensa giraba en torno a la inverosimilitud de los hechos y en la posible acción del demonio que tomaba la figura del reo para engañar a las delatantes que creían verle a él. Así, se sorprendió al oír que

había diez años, [una de las testigos] vio al reo dentro de la clausura para las torpezas que expresa y no es verosímil que a los doce de edad estuviese ya su naturaleza y capacidad en estado de tanto exceso de delitos, siendo los que se refieren en esta causa de los más graves y atroces y que por ello, deben ser tanto más claras las pruebas, siendo en la mayor parte sujetas a demostraciones ciertas, como son las señales y heridas de los pechos, el defenso de virginidad con los usos y partos que se refieren, [...] que por lo que hace a infanticidios tampoco se ha inquirido el paradero de los cadáveres o de algún hueso, que hiciese cierto el cuerpo del delito, para tratar después del reo, y de su pena, y así concluyó en definitiva, pidiendo se le tratase con misericordia en atención con sus pocos años.

Negó los cargos hasta el final y las retractaciones de algunas de las religiosas, entre ellas Sor María de los Dolores Montero y Sor Rosa Montilla, vinieron a reforzar la duda de los inquisidores respecto a la realidad de lo que contaban las monjas. Una de las delatoras se desdijo de sus declaraciones anteriores, debidas a "sueños e ilusiones", pero los inquisidores opinaron que podía ser resultado de las persuasiones y amenazas ejercidas por las demás religiosas.

El 28 de abril de 1767, tras escuchar la acusación de que era objeto, Alonso de Osuna

27 AHN, Inq. Leg. 2692, Caja 1, Exp. 120. 
permaneció negativo, manifestando una grande extrañeza al oír los cargos como especies novísimas y muy ajenas de su noticia, confesando únicamente delitos de lujuria en algunas mujeres seglares y con doña Rosa Montilla, religiosa profesa de velo negro en dicho convento de Santa Clara, con ésta en uno de los locutorios, reduciéndose a algunos tactos que pudieron facilitar por la reja de él, y conversación de ambos enteramente lujuriosa pero sin calidad de oficio ${ }^{28}$.

La actitud del joven y su lógica contrastan con la descripción hecha por un inquisidor quien escribió, el 27 de agosto de 1771, que

reduciéndose sus delitos a deslices lascivos desde su niñez, sin calidad alguna de oficio, es más de admirar en persona que suena como autor y fomento de toda la maraña, y que tratado de cerca se descubre muy desde luego su cortedad de luces y talentos en materias tan sútiles, raras y peregrinas a un hombre de vulgar esfera y toscos modales ${ }^{29}$.

Sabemos que el encausado pidió una audiencia el primero de septiembre de 1770 ,

en que dijo que solamente la pedía, para hacer la más humilde instancia, a fin de que se le pusiese en libertad, porque ya le faltaban fuerzas para tolerar tan larga prisión y encierro, pues llevaba ya cinco años de penosa cárcel, y en lo que alcanza se halla sin culpa cuyo conocimiento toque al Santo Oficio.

En 1771, en un informe entregado al Consejo de la Suprema se decía:

Alonso de Osuna, preso, respecto a la carencia de prueba que produce su causa, y las demás en que es citado, y que su negativa con declaración franca de sus lujuriosos desórdenes que le han ocasionado por más de cinco años la estrecha prisión de un calabozo, privado de oír misa y demás pasto espiritual, por todo ello soy de opinión que no es acreedor al presente de pena alguna, y sólo por atender al bien de su alma, que sea instruído en el Santo temor de Dios, y Doctrina Cristiana se le manden hacer unos ejercicios espirituales por espacio de un mes, con confesión general encargado en la comunidad que se le señale a persona docta que lo dirija, instruya y fortifique, y que hecho esto, para evitar discursos en Antequera, de figurarlo reo general, se le permita que por sólo el espacio de ocho días pueda residir en dicha ciudad en la casa de su padre con privación de todo trato y entrada en el convento, encargado en este tiempo al comisario, y pasado que sea, se le notifique salga luego de dicha ciudad, con absoluta privación de volver a ella para conseguir por este medio evitar el peligro que su residencia pudiera ocasionar allí, y que con esto se suspenda igualmente su causa ${ }^{30}$.

\footnotetext{
28 AHN, Inq. Leg. 2692, Exp. 144.

29 AHN, Inq. Leg. 2692, Caja 1, Exp. 120.

30 Ibid.
} 
El consejo ordenó, por carta del 20 de noviembre de 1771: «que interim se le devuelve definida la causa de Alonso de Osuna, dé a este algún desahogo, o ensanche en las cárceles, y disponga el que se le haga un vestido correspondiente a su oficion ${ }^{31}$.

\section{ACTUACIÓN DEL SANTO Oficio HASTA 1767}

Los manuscritos ponen de manifiesto una notable evolución en las actuaciones del Santo Oficio. Destacan dos etapas. La primera, hasta 1767, es dominada por la credulidad del comisario Zenzano, encargado de recoger las primeras declaraciones en Antequera, y de los inquisidores granadinos quienes sugieren la aplicación del tormento al reo y el reconocimiento de las celdas de las religiosas doña María de los Dolores Montero y doña Rosa Montilla, encarcelando a las dos mujeres por su presunta complicidad. La segunda fase corresponde al informe de 1771, en que otros tres inquisidores denuncian la "hipocresía" de las religiosas, afirmando que no creen en la realidad de los hechos relatados.

El Comisario Zenzano calificado de "sujeto de gran juicio y literatura" opinó que "convendría la pronta prisión del Alonso de Osuna que se conceptuaba cabeza o caudillo de estas juntas que aún no cesaban, y que su prisión pondría en grave recelo a los demás cómplices para que se delatasen" ${ }^{32}$.

En la calificación presentada a la vista de los extractos del proceso y de las audiencias y repuestas del reo, los inquisidores "dijeron que no evacuaba, ni satisfacía con la general, ni particular negativa de todos los hechos y dichos contra fidem, y así le dieron en lo subjetivo por reo convicto y negativo, confirmando las censuras antecedentes. El tribunal votó, asistiendo dos Inquisidores y el ordinario a 11 de febrero de 1767 a que fuese puesto en el tormenton. Por nuestra parte, no hemos podido verificar si le fue aplicado realmente.

Sí sabemos que el Consejo a 29 de mayo de 1767 mandó

que la Montilla, Montero fuesen presas en cárceles secretas con secuestro de su peculio y se les siguiese sus causas hasta definitiva [...] Que se procurara poner particular cuidado en reconocer las celdas de estas dos reos por si se encontraban papeles, ungüentos u otra cosa que fuese conducente a su causa, como también que no supiesen una de otra esta providencia de su prisión.[...] Que si éstas en sus respectivas audiencias, y respuestas a los cargos no confesasen tener he-

\footnotetext{
31 AHN, Inq. Leg. 2692, Caja 1, Exp. 145.

32 AHN, Inq. Leg. 2692, Exp. 92.
} 
rido el pecho y haber parido, se pasase por medio del cirujano del tribunal y una comadre a hacer el reconocimiento respectivo ${ }^{33}$. Esta orden se recibió en el Tribunal de Granada a 10 de junio de 1767.

La equivocación del Santo Oficio, en esa primera fase del proceso es obvia, aludiendo el informe de 1771 a una "montaña de humo que formó su cuerpo con anticipada aceleración antes que lo entendiese el Tribunal" por culpa del confesor ordinario de aquel tiempo, fray Agustín Ponce ${ }^{34}$.

Aparte de la clara responsabilidad del confesor en los delirios "mitómanos" ${ }^{35}$ de las monjas, otro elemento importante puede favorecer la comprensión de estos problemas originados en la vida interna del convento. Por carta orden, fechada en Sevilla el 19 de octubre de 1766, nos enteramos de que

no debiendo haber en el convento de Santa Clara más de treinta religiosas, hoy hay cincuenta, de que se sigue falta de observancia. Manda que según vayan muriendo se reduzca el número a solas treinta, y que salgan luego las que no hayan llegado a los quince años y por consiguiente empezado el noviciado ${ }^{36}$.

33 En el proceso de Logroño de 1610 , las personas sospechosas de pertenecer a la secta de las brujas se reconocían gracias a una mancha en el ojo izquierdo. También las religiosas de Antequera se distinguieron de los demás con unas heridas en los pechos en señal de esclavitud del Demonio. Pero, añade el inquisidor Don Joaquín Arias de Urbina, "yo no reputo suficientemente probado el cuerpo del delito en esta parte porque se encuentre una y otra religiosa con tales heridas que pueden provenir de otras causas a vista de que, habiendo reconocido a Doña María de los Dolores Montero testificada de tener herida en el pecho, y encontrándose en efecto en el reconocimiento tener una menuda cicatriz, que dijo ella haberle resultado de una viruela que tuvo en el sitio, los peritos la han calificado de tal en vista de su figura orbicular, y que si la herida hubiese dimanado de otra causa artificiosa tendría la cicatriz otra configuración [...] por lo que me inclino más a que no debe tenerse por distintivo de delincuentes en la complicidad por encontrarse en algunos de los procesos que el abrirse la herida se dirigía a aumentar, y excitar la delectación venérea." [AHN, Inq. Leg. 2092, Exp. 61].

34 AHN, Inq. Leg. 2692, Exp. 61.

35 A este respecto Julio Caro Baroja desarrolla, aplicándolo al caso de las brujas de Fuenterrabía, el concepto de mitomanía que E. Dupré presentó en, Pathologie de l'imagination et de l'émotion (Paris, 1925). Entre las diversas formas de mitomanía definidas por este autor, nosotros destacamos la más próxima a nuestro objeto de estudio: la mitomanía considerada como un fenómeno inspirado por la influencia de "una sugestión extraña. Julio Caro BAROjA, "Las brujas de Fuenterrabía (1611)», RDTP, III (1947), pp. 189-204.

36 AHN, Inq. Leg. 3723, Exp. 129. 


\section{EL INFORME DE 1771}

Tres inquisidores entregaron un informe, con fecha de 27 de agosto de 1771, que recogía los datos más importantes del caso, se trata de don Joaquín Arias y Urbina, don Joaquín de Samaniego y Salamanca y don Juan Jacinto de Varaez. Analizan en su conjunto las declaraciones efectuadas, poniendo de relieve las numerosas contradicciones e inverosimilitudes como pruebas de las mentiras o equivocaciones de las monjas, calificadas en los manuscritos de "hipocresías". Propusieron varias soluciones para cortar de raíz la plaga de los delirios de algunas religiosas que alcanzaban, como lo hemos comprobado, un grado de inhumanidad sorprendente en unas mujeres "esposas de Dios" que se convirtieron en adoradoras del demonio, entregándose, en su imaginación desenfrenada, a las actividades brujescas más lujuriosas.

Don Joaquín Arias de Urbina escribió acerca de las declaraciones hechas por las religiosas:

tampoco hallo fundamento probado en bastante forma que persuada han entrado hombres en la clausura por Arte Diabólico y salido de ella Monjas por el mismo Arte Diabólico para conseguir sus fines torpes; teniendo por más verosímil que las fragilidades que se hayan verificado en el convento las habrá facilitado la malicia $\mathrm{y}$ astucia humana por los medios naturales que el Enemigo haya sugerido como sucedió $^{37}$.

En su análisis, demostró la poca fiabilidad de las declaraciones de las religiosas como la de doña María San Rafael Losada,

que es la que se ha mantenido constante en sus declaraciones contra sí y contra otras personas. [...] Depone congregaciones diabólicas en que se halló año de 1761, que sería de edad de 13 años, corta edad para que merezca crédito en materia tan sujeta a engaños, dirigió su primera denuncia por el visitador Fray Pedro Romero, y debe entrar el recelo de que se movió con fines particulares motivados de la visita y alborotos que causó.

A juicio del mismo inquisidor, parece también inverosímil

el que hubiese habido tantos partos naturales, o por modo natural (pues sólo a la Montero le cuenta tres), infanticidios, no constando como no consta en los procesos justificado el cuerpo del delito, ni el de los hechos previos y subsiguientes a casos de tanto bulto y embarazo, y que en una comunidad hubiesen medio, ni arbitrio para que se ocultase, y disimulase, parece también especie que merece desprecio ${ }^{38}$.

37 AHN, Inq. Leg. 2692, Caja 1, Exp. 120.

38 Ibid. 
El inquisidor Arias de Urbina pensaba que

no merecen aprecio las declaraciones de María de los Dolores en que delata cómplices, especialmente cuando se observa en ellas, a mi entender, tantas señales de inverosimilitud y falsedad, una de ellas ver que implica en octubre de 1767 a doña María de Ortega (actual Prelada del convento), en la complicidad y concurrencia a junta diabólica. [...] hasta julio del año presente de 1771, aunque se la ha estrechado en las audiencias con reconvenciones, y últimamente con la eficacia que contiene la acusación de revocante que puede considerarse como una especie de tortura, y después de todo se mantiene en su revocación de cuanto ha declarado contra cómplices ${ }^{39}$.

Asimismo, opinaba que la visita que se hizo en el convento en 1764 fue el desencadenante de toda la historia puesto que de ella

dimanaron las más de las denuncias hechas al Santo Tribunal por religiosas que ocurrieron a él espontáneamente [...], relacionando en las denuncias hechos verdaderos, mezclados con hechos falsos, y dejando muy difícil de discernir lo verdadero de lo falso y engañando las delatantes a sus respectivos confesores (a lo que es de presumir) y por medio de ellos al Tribunal ${ }^{40}$.

Para resolver esta enojosa situación, este inquisidor propuso que

a la religiosa doña María de San Rafael Losada se la mude a otro convento de su orden donde estará libre de los temores y amenazas de muerte que según los informes, y sus declaraciones, la han tenido sobresaltada, y también de otro mayor peligro cual considero es, el que la precisen a presenciar las juntas diabólicas y escándalos que en ellas se cometen (aunque ya llevo dicho que yo no lo creo).

Preconizó, asimismo, separar en conventos distintos a doña María Josepha Casasola y a doña María de los Dolores Montero advirtiendo que para suavizar la separación, convenía que se dispusiese con prohibición de manifestar provenía de orden del Santo Oficio ${ }^{41}$. A María de los Dolores Montero "presa, en atención a su quebrantada salud, y que ella misma solicita con instancia no volver a su convento de Antequera, se le asigne al convento de religiosas llamadas de los Angeles en esta ciudad de Granada y se suspenda su causa" ${ }^{42}$.

Por su parte, el inquisidor Samaniego y Salamanca era del mismo parecer, expresando su convicción de que para despachar rápidamente

$\begin{array}{ll}39 & \text { Ibid. } \\ 40 & \text { Ibid. } \\ { }_{41} & \text { Ibid. } \\ { }_{42} & \text { Ibid. }\end{array}$


este asunto, parecía conveniente, en un primer momento, cambiar a las religiosas de convento. A este respecto declaró en su dictamen que ren asunto de tanta gravedad se necesita de suma consideración" proponiendo separar a las principales encausadas "por el tiempo que fuere necesario en conventos distintos" 43 .

El dictamen del inquisidor don Juan Jacinto de Varaez incluía algunas matizaciones respecto a los anteriores, en base a que las religiosas pertenecían a la alta sociedad de Antequera. Ampliando este asunto, precisó en una carta que "las religiosas que suenan en los procesos son de muy esclarecidas familias en estos países de Andalucía [algunas son parientas de marqueses, condes, etc...], que aunque hubiera prueba contra ellas es justo se haga esto presente a V.S. y al Comisario" ${ }^{44}$.

Y aunque pudiera parecer conveniente la separación de las dos hermanas Casasolas, las dos Losadas, la Lega Concepción, y alguna otra destinándolas a otros conventos de su filiación de varios pueblos de Andalucía, lo contemplo todo del mayor ruido y estrépito en conocido y grave perjuicio de la fama y opinión del convento de Antequera, sus individuos, y las muchas familias de la primera distinción que tienen prendas en la tal comunidad, [...] por lo cuanto me parece conviene ninguna otra mutación a otros conventos, ni tampoco que sea conducente el que estas causas se sigan por el método judicial ordinario ${ }^{45}$.

Finalmente, parece ser que fue éste el criterio que terminó imperando, aunque carecemos de los datos definitivos. La mayoría de las religiosas permanecieron en el convento bajo la estricta vigilancia de las autoridades eclesiásticas, según se desprende del informe de referencia donde se dice:

se leerá a la comunidad de religiosas de Santa Clara, un Edicto General de Fe con su Anatema, el de solicitante in confesione, y el que se lee a las comunidades de religiosos. [...] Que al mismo tiempo conceda V.A. un perdón general por todo lo pasado a todas las religiosas que, espontáneamente y con verdadero arrepentimiento, declaren sus delitos que hubieren cometido pertenecientes al Santo Oficio ${ }^{46}$.

\section{CONCLUSIÓN}

La historia descrita en las páginas anteriores nos lleva a efectuar unas reflexiones finales sobre algunos de los aspectos más significativos de este proceso excepcional que duró más de ocho años. Aunque se trata de un

$\begin{array}{ll}{ }_{43}^{43} & \text { Ibid. } \\ { }_{44} & \text { Ibid. } \\ { }_{45} & \text { Ibid. } \\ { }_{46} & \text { Ibid. }\end{array}$


asunto aparentemente circunscrito a la vida interna de un convento, podemos considerarlo como un caso representativo de las creencias y convicciones populares de la España dieciochesca. Dentro de este contexto, destacan algunos hechos con más fuerza.

En primer lugar resalta la importancia indudable del confesionario y de la figura del confesor con respecto a las opiniones de las monjas. La "epidemia onírica" o los delirios "mitómanos" analizados en nuestro caso, revelan el ambiente supersticioso y erótico-religioso de la vida conventual. El clero, en su afán de combatir la plaga de la superstición que impregnaba la sociedad de la época, probablemente provocó, en algunos casos, efectos distintos a los deseados, bien a través de vías directas o indirectas como la confesión y los sermones.

Son reveladores, asimismo, los muchos datos que se aportan sobre la vida íntima en el convento. Llama la atención la corta edad de las monjas que ingresaban de novicias a los 12, 13 ó 16 años, sin ningún tipo de experiencia previa, y a las que se sometía a una presión disciplinaria y ritual que podía propiciar algunos excesos. También el número de monjas - en algunos textos manejados se nos habla de cincuenta cuando debieran habitar en el convento no más de treinta-, pudo influir en el suceso. Todo este conjunto de factores de muy variado carácter contribuyeron a crear un clima adecuado para que una persona imprevista, en este caso Alonso de Osuna, prendiera con toda facilidad, en la colectividad conventual, las llamas de la herejía, la superstición o la superchería.

En cuanto a la actuación del Santo Oficio, se comprueba el celo con que trabajaron los inquisidores para averiguar toda la verdad a lo largo de tantos años, incluso imponiendo su criterio sobre la falsedad de los hechos presentados, negándose a castigar con severidad a los protagonistas de las causas. Es preciso también recordar la cautela recomendada por algún inquisidor para reducir los efectos de un escándalo social inevitable que empañaría el honor del convento, así como el de las "muy esclarecidas familias en estos países de Andalucía a las que pertenecían muchas de las religiosas.

Todo este conjunto de hechos nos lleva a una postrera reflexión: los sucesos acaecidos en el convento de Santa Clara de Antequera, a pesar de su ámbito reducido, pueden ser considerados como un apunte de los problemas que la sociedad española tenía en esta centuria sobre los temas religiosos en general. Sería deseable comprobar en un estudio posterior, si el caso de las monjas de Antequera fue un fenómeno aislado o si se dieron casos similares en otras zonas de la Península en el siglo XVIII y principios del XIX.

VALÉRIE MOLERO

Universidad de Provence

Aix en Provence 
Este artículo estudia un presunto caso de complicidad diabólica acaecido en el convento de Santa Clara de Antequera en la segunda mitad del siglo xviI. Se analizan las actuaciones de las religiosas que denunciaron a un profesor de música por hechicero, así como la investigación llevada a cabo por el Santo Oficio durante más de ocho años. El convento de Santa Clara cobra especial interés por cuanto representa un microcosmos donde se dan cita algunos de los problemas religiosos, vinculados con la mentalidad supersticiosa que impregnaba la sociedad española dieciochesca.

This article covers a presumed case of diabolic complicity which took place in the Santa Clara convent at Antequera in the second half of the eighteenth century. The article analyzes the actions of the nuns who had denounced a music professor for sorcery, as well as the investigation undertaken by the Inquisition over more than eight years. The Santa Clara convent is of special interest since it manifests a microcosm in which appears some of the religious problems linked to the superstitious mentality that impregnated the Spanish society during the eighteenth century. 